\title{
Mucin Production by Human Colonic Carcinoma Cells Correlates with Their Metastatic Potential in Animal Models of Colon Cancer Metastasis
}

\author{
Robert S. Bresalier," Yaron Niv," James C. Byrd,“ Quan-Yang Duh,“ Neil W. Toribara," Richard W. Rockwell," \\ Rajvir Dahiya," and Young S. Kim* \\ Veterans Administration Medical Center and Departments of ${ }^{*}$ Medicine and ${ }^{\ddagger}$ Surgery, University of California, \\ San Francisco, San Francisco, California 94121
}

\begin{abstract}
Patients with mucinous colorectal cancers characteristically present with advanced disease, however, the relationship between mucin production by colon cancer cells and their metastatic potential remains unclear. We therefore sought to define the relationship between mucin production by human colon cancer cells and metastatic ability by employing animal models of colon cancer metastasis. LS LiM 6, a colon carcinoma cell line with high liver metastasizing ability during cecal growth in nude mice produced twofold more metabolically labeled intracellular mucin and secreted four- to fivefold more mucin into the culture medium compared to poorly metastatic parental line LS174T. This was accompanied by a similar elevation in poly $(\mathbf{A})^{+}$RNA detected by blot hybridization with a human intestinal mucin cDNA probe, and increases in mucin core carbohydrate antigens determined immunohistochemically.

Variants of LS174T selected for high (HM 7) or low (LM 12) mucin synthesizing capacity also yielded metastases after cecal growth and colonized the liver after splenic-portal injection in proportion to their ability to produce mucin. Inhibition of mucin glycosylation by the arylglycoside benzyl- $\alpha-N$-acetylgalactosamine greatly reduced liver colonization after splenicportal injection of the tumor cells. These data suggest that mucin production by human colon cancer cells correlates with their metastatic potential and affects their ability to colonize the liver in experimental model systems. (J. Clin. Invest. 1991. 87:1037-1045.) Key words: carbohydrates • glycosylation • adenocarcinoma $\bullet$ cecum $\cdot$ liver
\end{abstract}

\section{Introduction}

Patients with mucinous adenocarcinomas of the colon often present with advanced disease, and have been reported to have a poor prognosis (1-6). Whereas many authors report a lower survival for patients with mucinous cancers compared to those with "nonmucinous" tumors, others have failed to find a significant correlation between this histologic pattern and prognosis

Presented in part at the Digestive Disease Week of the American Gastroenterological Association, May 1989, in Washington, DC, and published in abstract form (1989. Gastroenterology. 96:A57).

Address reprint requests to Dr. Bresalier, GI Research Lab (151M2), VA Medical Center, 4150 Clement St., San Francisco, CA 94121.

Received for publication 25 June 1990 and in revised form 29 October 1990

J. Clin. Invest.

(C) The American Society for Clinical Investigation, Inc.

0021-9738/91/03/1037/09 \$2.00

Volume 87, March 1991, 1037-1045
(6). This controversy may relate in part to the lack of adequate quantitation of cancer mucin production in most histochemical studies, and to variable definitions of "mucinous carcinoma" in the literature. Some studies suggest, for example, that only tumors which produce large amounts of mucin may be associated with a poor prognosis (4).

The relationship between mucin production by colon cancer cells and their metastatic potential is even less clear. The incidence of local invasion and recurrence appears high for mucinous colorectal cancers $(4,6)$, but the incidence of distant metastasis is poorly documented.

A detailed understanding of the biological behavior of human colon cancer cells and metastasis may be furthered by appropriate in vivo models which accurately reflect the events in this complex process. We have recently described an animal model for colon cancer metastasis $(7,8)$ which was used to establish and characterize human colon cancer cells which differ in their liver-metastasizing ability during cecal growth. Colon cancer cells which produce high or low amounts of mucin relative to the same parental cell line have also been previously selected in our laboratory (9). In the current series of experiments we were therefore able to quantitate mucin production by human colon cancer cells of known metastatic ability, and conversely to assess the metastatic potential of colon cancer cells which differ in their capacity to produce mucin. The effect of mucin glycosylation on experimental liver colonization was also studied using a compound which competitively inhibits mucin glycosylation with little effect on cell growth or viability (10).

\section{Methods}

Cell lines. Parental colon cancer cell line LS174T was derived from a well-differentiated human colonic adenocarcinoma (11), and has been characterized extensively, including its ability to produce mucin in vitro (9), and when grown subcutaneously in athymic nude mice (12). Cells injected into the cecal wall of nude mice produce well-differentiated primary colon cancers with little metastatic ability (7).

LS LiM 6, a derivative of LS174T with high liver-metastasizing ability during cecal growth, was established by serially selecting cells which metastasized from cecum to liver as previously described (7). These cells form well-differentiated mucinous carcinomas in nude mice, with large glands containing PAS-positive ${ }^{1}$ mucin comprising $\sim 50 \%$ of the tumor area. HM7 and LM12 are variants of LS174T which produce high and low amounts of mucin, respectively, relative to the parental cell line, and were selected by a replica plating and immunoscreening method as previously described (9). HM7 secretes approximately twofold more mucin in culture and contains twofold

1. Abbreviations used in this paper: benzyl- $\alpha-G a l N A c$, benzyl- $\alpha-N$ acetylgalactosamine; CMF, calcium and magnesium-free phosphate buffered saline; GIcNAc, $N$-acetylglucosamine; PAS, periodic-acidSchiff. 
more intracellular mucin compared with LS174T, whereas LM12 produces $\sim 30 \%$ less mucin overall compared with the parental line (9). HM7 forms well differentiated tumors in nude mice, with prominant glands containing PAS-positive mucin comprising $40-50 \%$ of the tumor area. In contrast, LM 12 xenografts contain fewer mucin-containing glands comprising $<10 \%$ of the tumor area (8).

All cell lines were grown and maintained in DMEM supplemented with $10 \%$ fetal bovine serum, penicillin $(100 \mathrm{U} / \mathrm{ml})$, and streptomycin $\left(100 \mu \mathrm{g} / \mathrm{ml}\right.$ ), in a $7 \% \mathrm{CO}_{2}$ environment. Early passage cell lines (passaged fewer than 15 times) were used for all studies.

Metabolic labeling of cells. Cells were grown to confluency in 25$\mathrm{cm}^{2}$ tissue culture flasks as above, then labeled for $24 \mathrm{~h}$ in low-glucose DME H-16 medium (Gibco, Grand Island, NY) containing $1 \mu \mathrm{Ci} / \mathrm{ml}$ $\left[{ }^{3} \mathrm{H}\right]$ glucosamine (sp act $\left.30 \mathrm{Ci} / \mathrm{nmol}\right)(9)$. Cell numbers were determined from parallel flasks. After $24 \mathrm{~h}$, the cells were chilled on ice and the medium removed. The cell layer was scraped in PBS pH 7.4 and added to the medium for centrifugation ( $600 \mathrm{~g}$ for $10 \mathrm{~min}$ ). The medium supernatant was collected, and the cell pellet sonicated on ice in $10 \mathrm{mM}$ Tris buffer $\mathrm{pH}$ 8.0. Cell homogenates were ultracentrifuged at $100,000 \mathrm{~g}$ for $1 \mathrm{~h}$, and the supernatant designated as the cytosol component.

Gel filtration of labeled glycoproteins. The medium and cytosol fractions were subjected to gel filtration on sepharose CL-4B columns $(1 \times 43.5 \mathrm{~cm})(9,10,12)$. Samples of $1 \mathrm{ml}$ were applied, and the columns eluted at $4^{\circ} \mathrm{C}$ with $10 \mathrm{mM}$ Tris- $\mathrm{HCl}$ buffer, $\mathrm{pH}$ 8.0. Fractions of $0.8 \mathrm{ml}$ were collected and radioactivity determined by liquid scintillation counting. The results were corrected for counting efficiency and cell number, and expressed as counts per minute per $4 \times 10^{6}$ cells as previously described (9).

Chemical and enzymatic degradation. Void volume material was analyzed subsequent to reductive cleavage of $O$-glycosidic linkages ( $\beta$ elimination), or digestion with trypsin, hyaluronidase, heparitinase, or chondroitinase $\mathrm{ABC}$ as previously described (9).

CsCl centrifugation. $\mathrm{CsCl}(0.54 \mathrm{~g} / \mathrm{ml})$ was added to the void volume material and the solution centrifuged for $72 \mathrm{~h}$ at $160,000 \mathrm{~g}$ in a model SW-41 rotor (Beckman Instruments, Inc., Fullerton, CA) at $5^{\circ} \mathrm{C}$. Fractions of $1.0 \mathrm{ml}$ were removed and weighed to determine density and counted.

Mucin RNA blot analysis. RNA purification and poly $(\mathrm{A})^{+}$RNA isolation, gel electrophoresis, transfer to nylon membranes, and hybridization probe analysis were performed as previously described (13). $\operatorname{Poly}(\mathrm{A})^{+}$RNA blots were probed with cDNA SMUC 41, which encodes a threonine- and proline-rich consensus sequence of human intestinal mucin (14). Control lanes were examined with a probe encoding a 960-bp fragment of the human glyceraldehyde-3-phosphate dehydrogenase gene (15).

Glycosyltransferase assays. Cultured cells (75\% confluent monolayer cultures) were washed three times with PBS and harvested by scraping into $8 \mathrm{ml}$ PBS with a cell scraper. Cells were centrifuged, and the cell pellet was suspended and sonicated in $1 \mathrm{ml}$ PBS (pH 7.1). Aliquots were used directly for glycosyltransferase assays or frozen at $-70^{\circ} \mathrm{C}$.

$\beta 1-4$ Galactosyltransferase activity was determined as previously described (16) using a reaction mixture consisting of $0.1 \mathrm{M}$ cacodylate buffer (pH 6.8), $20 \mathrm{mM} \mathrm{MnCl}_{2}, 200 \mu \mathrm{M}$ ATP, $10 \mathrm{mM}$ GlcNAc, 17-20 $\mu \mathrm{M}$ UDP- $\left[{ }^{3} \mathrm{H}\right]$ galactose $(50,000-60,000 \mathrm{cpm}), 50-100 \mu \mathrm{M}$ cellular protein, and $0.1 \%$ triton X-100 in a total volume of $100 \mu \mathrm{l}(17)$.

Polypeptidyl $\mathrm{N}$-acetylgalactosaminyl transferase activity was determined using myelin basic protein $(100-200 \mu \mathrm{g})$ as acceptor and $5.4 \mu \mathrm{M}$ UDP $\left[{ }^{14} \mathrm{C}\right]-N$-acetylgalactosamine $(40,000 \mathrm{cpm})$ as donor. Assays for $\beta 1-3$ galactosyltransferase activity utilized asialo-ovine submaxillary mucin $(100-200 \mu \mathrm{g})$ as acceptor and $0.12 \mu \mathrm{M}$ UDP $\left[{ }^{3} \mathrm{H}\right]$ galactose $(14,000 \mathrm{cpm})$ as nucleotide-sugar donor. Assay mixtures contained 0.1 $M$ cacodylate buffer (pH 6.8), $20 \mathrm{mM} \mathrm{MnCl}_{2}, 0.1 \%$ triton X100, 200 $\mu \mathrm{M}$ ATP, and 25-100 $\mu \mathrm{g}$ enzyme in a total volume of $100 \mu \mathrm{l}$ (17). Reaction mixtures were incubated at $37^{\circ} \mathrm{C}$ for $90 \mathrm{~min}$, and the reaction terminated by the addition of $2 \mathrm{ml}$ ice-cold $1 \%$ phosphotungstic acid in $0.5 \mathrm{M} \mathrm{HCl}$. Precipitates were washed three times with cold phospho- tungstic acid and dissolved in $600 \mu \mathrm{l}$ Omnisol tissue solubilizer (ICN Biomedicals, Inc., Irvine, CA), and counted with $10 \mathrm{ml}$ Omnifluor (New England Nuclear, Boston, MA) toluene scintillation cocktail. Net radioactivity transferred to exogenously added acceptor was determined after subtracting the amount of radioactivity transferred to endogenous acceptors.

All assays were performed within the linear range of both enzyme concentration and incubation time. The amount of donor (unlabeled and labeled) used in each case yielded optimum transfer of labeled donor to acceptor.

Cecal injection. Confluent cultures were harvested by brief trypsinization $(0.05 \%$ trypsin- $0.02 \%$ EDTA in HBSS without calcium and magnesium), washed several times with calcium and magnesium-free phosphate-buffered saline (CMF), and resuspended at a final concentration of $5 \times 10^{7}$ cells $/ \mathrm{ml}$ in serum-free medium. The presence of single-cell suspensions was confirmed by phase-contrast microscopy, and cell viability was determined by Trypan blue exclusion. Pathogenfree BALB/c NCR-NU athymic mice (3- to 5-wk-old females obtained from the National Cancer Institute, Frederick, MD) were anesthetized, the cecum exteriorized, and $5 \times 10^{6}$ viable tumor cells in $0.1 \mathrm{ml}$ injected into the cecal wall as previously described $(7,8)$. The cecum was replaced in situ, and the abdomen closed with stainless steel clips. After $6 \mathrm{wk}$ animals were sacrificed by cervical dislocation and the abdominal organs and thorax examined for the presence of macroscopic "primary" cecal tumors and metastases. Macroscopic metastases were defined as those visible to the naked eye. Organs including cecum, liver, mesenteric nodes, and lungs were removed and fixed in $10 \%$ formalin for $24 \mathrm{~h}$. Representative tissues were embedded in paraffin and serial $5-\mu \mathrm{m}$ sections cut, stained with hematomylin-eosin and periodic-acidSchiff (PAS), and examined by light microscopy to verify the presence of metastases.

Splenic injection (liver colonization assay). The ability of the various tumor cells to colonize the liver after entry into the hepaticportal system was tested in a modification of a splenic injection model $(18,19)$, as previously described (16). Tumor cells were grown to confluency in $75-\mathrm{cm}^{2}$ tissue culture flasks, harvested as described for cecal injection, and resuspended in serum-free DMEM at a concentration of $10^{7}$ cells $/ \mathrm{ml}$. Athymic nude mice were anesthesized with methoxyfluorance by inhalation, prepared sterilely, and the spleen exteriorized through a flank incision. One million cells in $100 \mu$ l were slowly injected into the splenic pulp through a 27-gauge needle over $1 \mathrm{~min}$, followed by splenectomy $1 \mathrm{~min}$ later. Animals were sacrificed 3-4 wk later, the livers removed and weighed, and tumor nodules were counted.

The immediate fate of tumor cells after splenic injection was determined by injection of IdUR-labeled tumor cells. Cells were grown as above and $0.5 \mu \mathrm{Ci} / \mathrm{ml}\left[{ }^{125} \mathrm{I}\right]$ IdUR was added to culture medium $24 \mathrm{~h}$ before harvesting (16). This concentration of isotope labels $>95 \%$ of tumor cells without affecting viability. Cells were prepared and injected into the splenic pulp as described above. Animals were sacrificed 10 min after injection, and the livers removed. The radioactivity present in the spleen (removed after injection), liver, and remaining organs of each animal was determined by gamma-counting in a model 7000 counter (Beckman Instruments Inc.).

Liver colonization after inhibition of mucin glycosylation. Tumor cells were grown to $50 \%$ confluency in $75-\mathrm{cm}^{2}$ tissue culture flasks as described above. The tissue culture medium was then aspirated, and replaced with fresh medium containing $2 \mathrm{mM}$ benzyl- $\alpha$ - $N$-acetylgalactosamine (benzyl- $\alpha$-GalNAc) (10). Cells were harvested $48 \mathrm{~h}$ later, and liver colonization assayed after splenic injection as above.

In a separate experiment, tumor cells were grown for $48 \mathrm{~h}$ in medium containing $2 \mathrm{mM}$ benzyl- $\alpha-\mathrm{GalNAc}$ as above. The cells were then washed three times with CMF, and the medium replaced with DMEM containing $10 \%$ FBS. After an additional $48 \mathrm{~h}$, the cells were harvested and liver colonization assayed after splenic-portal injection. Parallel flasks were grown for $96 \mathrm{~h}$ in DMEM plus FBS or DMEM containing 2 $\mathrm{mM}$ benzyl- $\alpha$-GalNAc ( $n=6$ animals per group).

Tumorigenicity of benzyl- $\alpha$-GalNAc-treated cells. The tumorigenic- 
ity of benzyl- $\alpha-N$-acetylgalactosamine-treated cells was verified and compared with untreated cells after subcutaneous injection into athymic nude mice. Cells were grown to confluency in the presence or absence of $2 \mathrm{mM}$ benzyl- $\alpha$-GalNAc as above, harvested, and resuspended to a concentration of $5 \times 10^{7}$ cells $/ \mathrm{ml}$ in serum-free DMEM. 5 $\times 10^{6}$ viable tumor cells in $0.1 \mathrm{ml}$ were inoculated subcutaneously into the left posterior flank of 3-5-wk-old athymic mice which were observed daily for tumor growth. Tumors were measured with a caliper at least every other day, and tumor volume calculated as previously described (9).

Immunocytochemistry. Cells were grown as above, and seeded into eight-well chamber slides (Lab-Tek, Bountiful, UT) at a density of 3 $\times 10^{5}$ cells per well, and grown to confluency in DMEM supplemented with $10 \% \mathrm{FCS}$ at $37^{\circ} \mathrm{C}$ in a $7 \% \mathrm{CO}_{2}$ atmosphere. Cells were then washed twice with PBS, fixed with $100 \%$ ethanol/5\% acetic acid (20), washed, and used for immunocytochemical studies using the streptavidin-peroxidase technique (21). For monoclonal antibodies, negative controls consisted of substituting normal mouse IgM for primary antibody and PBS for primary and secondary antibodies. In all cases, when primary antibody was omitted, a negative staining pattern was obtained. Controls for lectins substituted PBS for lectins in the reaction. Additionally, specificity was confirmed by incubating equal volumes of lectin and $0.5 \mathrm{M}$ hapten sugar before incubation with cells in duplicate chamber slides. Staining intensity was graded as weak $(+)$, moderate $(++)$, or strong $(+++)(20)$.

Statistical analysis. Statistical analyses were performed as determined to be appropriate by an independent analyst. These included the Fisher exact test (number of metastasis-bearing mice after cecal injection), unpaired Student's $t$ test (liver weight, percent of input counts detected in the liver, specific activity of glycosyltransferases), and the Mann-Whitney test (number of tumor nodules after splenic-portal injection). For the purposes of the latter analysis, if a liver contained $>500$ nodules (too numerous to count), an arbitrary value of 500 nodules was used.

\section{Results}

Mucin production by human colon cancer cells of known metastatic potential. Human colon cancer cell line LS174T, derived from a well-differentiated cancer, produced hepatic parenchymal metastases after cecal growth in 2 of 30 nude mice. This low metastatic rate is similar to that previously described for this cell line (7). Liver metastases from LS174T were grown in culture, expanded, reinjected into the cecum of additional animals, and the process repeated six times (7) to select LS LiM 6 which produced hepatic metastases in 11 of 15 animals bearing cecal tumors $(P<0.001 \mathrm{LiM} 6$ vs. LS174T).

In addition, LS LiM 6 colonized the liver to a greater extent than LS174T after introduction into the portal system. 4 wk after intrasplenic injection of LS LiM 6, the livers of all animals $(n=12)$ were substantially replaced by tumor (mean liver weight \pm SD $4.75 \pm 1.85 \mathrm{~g}$; tumor nodules too numerous to count), whereas LS174T ( $n=12$ animals) produced relatively little hepatic tumor burden (mean liver weight, $1.28 \pm 0.35 \mathrm{~g}$; range, 2-30 nodules; $P<0.001$ for difference in number of nodules). This difference in liver colonization was not the result of differences in the number of tumor cells initially reaching the liver, because this was similar 10 min after intrasplenic injection of $\left[{ }^{125} \mathrm{I}\right]$ dUR-labeled cells $(72.5 \pm 10.8 \%$ of input counts, LS174T; 74.9 $\pm 7.1 \%$, LS LiM $6 ; n=6$ animals per group; NS).

The production of high-molecular weight mucin-type glycoproteins by LS174T and LS LiM 6 was quantitated by size exclusion chromatography on Sepharose CL-4B. Cells were metabolically labeled with $\left[{ }^{3} \mathrm{H}\right]$ glucosamine, medium and cytosol fractions subjected to gel filtration, and the high-molecu- lar weight radiolabel in the void volume initially taken as representative of mucin (9). Fig. 1 shows the gel filtration profiles of newly synthesized labeled glycoproteins secreted into the medium and from the cytosol fractions of parental cell line LS174T and liver-metastasizing cell line LS LiM 6. Three separate experiments demonstrated a four- to fivefold $(4.83 \pm 0.55$, mean $\pm S D$ ) increase in high-molecular weight labeled material secreted into the medium by metastatic LiM 6 compared to LS174T, and a twofold $(2.00 \pm 0.14)$ increase in intracellular high-molecular weight radiolabel in the metastatic cell line. The high-molecular weight labeled material from the void volume was highly susceptible to alkaline borohydride reductive cleavage, but resistant to degradation by trypsin, chondroitinase $\mathrm{ABC}$, hyaluronidase, heparitinase, and $N$-glycanase, further indicating that this material is mucin (9). This was also supported by cesium chloride density centrifugation $(9,22)$.

Mucin poly $(\mathrm{A})^{+}$messenger RNA determined by blot hybridization with human intestinal mucin cDNA SMUC 41 (14) was found to be proportionally increased in LS LiM 6 compared to LS174T (Fig. 2), whereas control lanes probed with a cDNA encoding the glyceraldehyde-3-phosphate dehydrogenase gene showed equal signals.

The expression of the colon cancer-mucin-associated core carbohydrate structures T (Gal $\beta 3$ GalNAc), Tn (GalNac $\alpha \mathrm{Thr}$ ), and sialyl Tn (Sia $\alpha 6$ GalNAc) (23) was also elevated in LS LiM 6 compared to LS174T as determined by immunohistochemical analysis of cultured cells. Staining intensity for mucin structures was weak in LS174T and strong in LS LiM 6 (Fig. 3). This was accompanied by a 1.6-fold increase in $\beta 1,3$ galactosyltransferase (the enzyme responsible for synthesizing the mucin core structure Gal $\beta 3$ GalNAc) in LS LiM 6 (11.56 $\pm 1.22 \mathrm{pmol} / \mathrm{mg}$ protein per h, LS LiM 6 vs. 7.12 \pm 0.91 , LS174T; $n=5$ experiments with triplicate determinations; $P<0.001$ ), whereas there was no significant difference in polypeptidyl $N$-acetylgalactosaminyl transferase or $\beta 1,4$ galactosyltransferase activity between the cell lines.

Metastatic ability of human colon cancer cells which differ in their capacity to produce mucin. Cell lines LM 12 and HM 7 are variants of LS174T which produce low and high amounts of mucin, respectively, compared to the parental cell line, and have been well characterized as to their mucin production in vitro (9) and when grown as xenografts in nude mice (12). The spontaneous metastatic potential of these cell lines during cecal growth was compared to LS174T as previously described (7), as was their ability to colonize the liver after introduction into the hepatic portal system (16). Cecal injection of LM 12 or LS174T produced few metastases, whereas HM 7 produced regional lymph node or hepatic metastases in the majority of animals tested (Table I). In addition, these cell lines colonized the liver after splenic-portal injection in proportion to their ability to produce mucin (Table II, Fig. 4). Little hepatic tumor burden was evident 3 wk after introduction of LM 12 or LS174T into the portal system, whereas extensive liver colonization was seen after injection of high mucin-producing HM 7. These differences in liver colonization were not due to differences in the number of tumor cells reaching the liver after splenic injection as demonstrated by injection of [ $\left.{ }^{125} \mathrm{I}\right] \mathrm{dUR}$-labeled tumor cells. There were no significant differences in the number of tumor cells detected in the liver $10 \mathrm{~min}$ after splenic injection of the various cell lines $(66.6 \pm 2.2 \%$ of input counts, LM 12; $71.7 \pm 5.6 \%$ LS174T; $67.3 \pm 8.94 \%$, HM $7 ; n=8$ animals per group). 

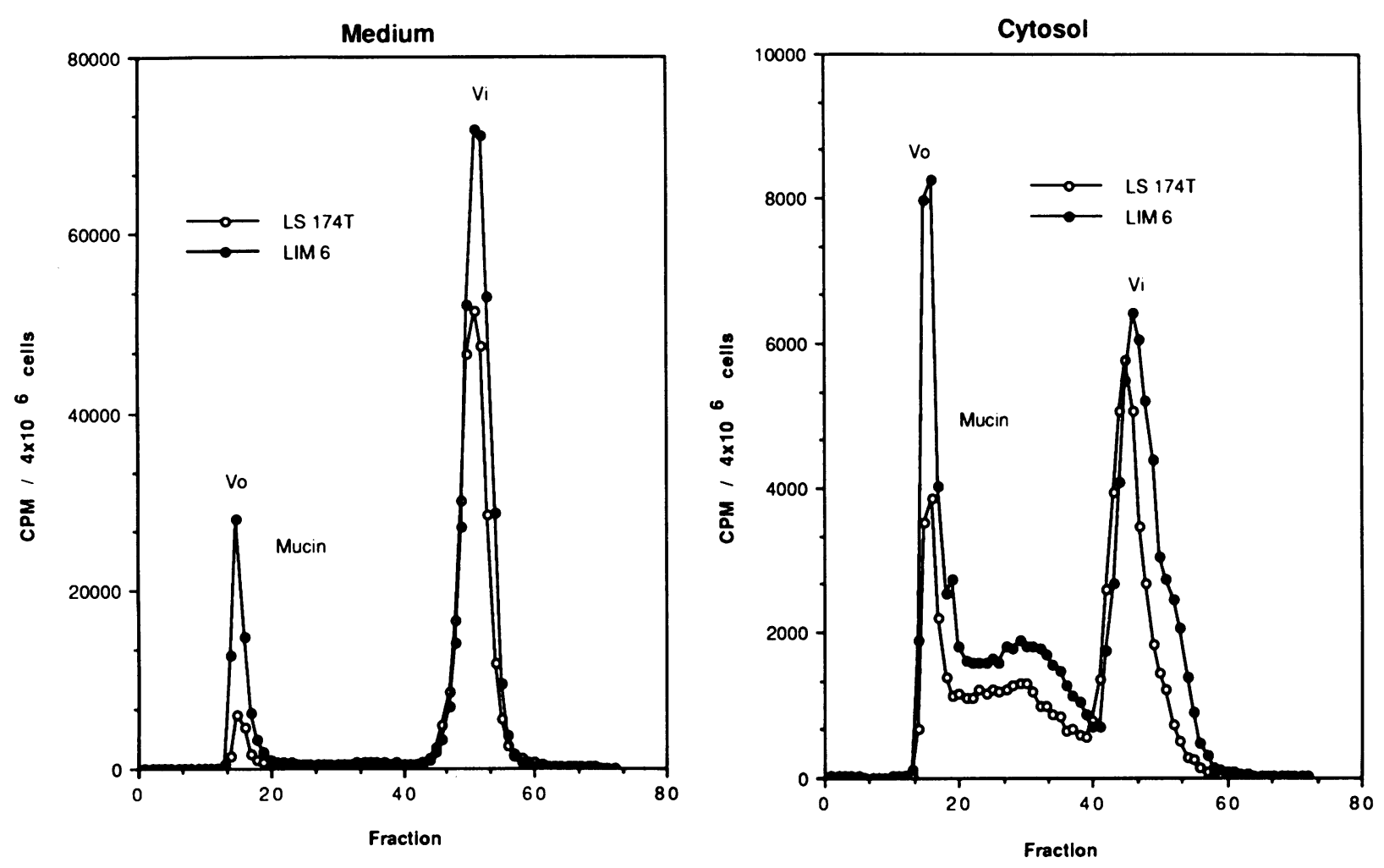

Figure 1. Sepharose CL-4B profiles of $\left[{ }^{3} \mathrm{H}\right]$ glucosamine-labeled glycoproteins secreted into the medium or from the cytosol fractions of parental human colon cancer cell line LS174T and its metastatic variant LS LiM 6. Results have been corrected for counting efficiency and cell number. $V o$, void volume; $V i$, included volume.

Liver colonization after inhibition of mucin glycosylation. The functional relationship between mucin production by colon cancer cells and their ability to colonize the liver was further studied by examining the effect of inhibition of mucin glycosylation on experimental liver colonization. Benzyl- $\alpha-N$ acetylgalactosamine (benzyl- $\alpha$-GalNAc) is an analogue of $N$ -

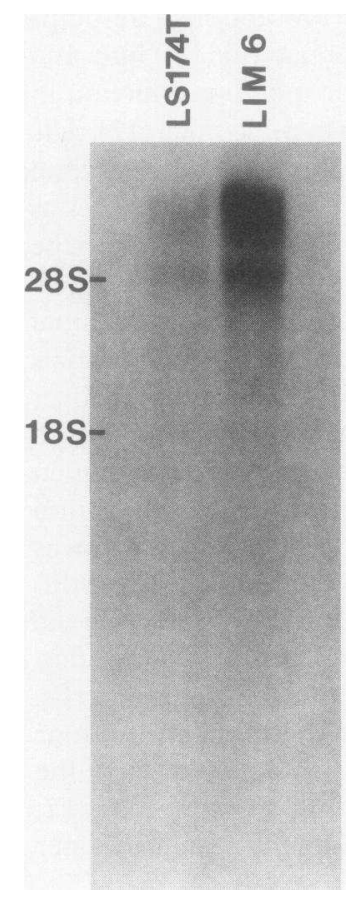

Figure 2. RNA blot analysis of mucin messenger RNA. Poly(A) ${ }^{+}$RNA samples $(0.5 \mathrm{mg})$ from human colon cancer cell line LS174T and its metastatic variant LS LiM 6 were analyzed using human intestinal mucin cDNA SMUC 41 as a probe. The $28-\mathrm{S}$ and 18-S rRNA subunits were used as size markers $(5,400$ and 2,100 bases, respectively). Control lanes probed with a cDNA encoding the glyceraldehyde3-phosphate dehydrogenase gene showed equivalent signals for the two cell lines (not shown). acetylgalactosamine, the first sugar in the mucin core region. This compound can compete as an acceptor for the elongation of oligosaccharides by glycosyltransferases and inhibit the formation of fully glycosylated mucin in a dose-dependent manner without affecting cell growth or viability (10). Growth of LS LiM 6 and HM 7 for $48 \mathrm{~h}$ in medium containing $2 \mathrm{mM}$ benzyl$\alpha$-GalNAc inhibited the production of high-molecular weight glycosylated mucin in these cell lines by $89 \%$ and $77 \%$, respectively (Fig. 5). A similar inhibition (82\%) has been previously demonstrated for parental cell line LS174T (10). Growth of mucin-producing cell lines HM 7 and LiM 6 in the presence of benzyl- $\alpha$-GalNAc before splenic-portal injection greatly reduced subsequent liver colonization compared to untreated controls (Fig. 6; Table III). Growth of cells in benzyl- $\alpha$-GalNAc before injection did not alter the number of viable tumor cells leaving the spleen and initially reaching the liver as determined by injection of $\left[{ }^{125} \mathrm{I}\right] \mathrm{dUR}$-labeled tumor cells. Tumorigenicity in athymic nude mice was similar after subcutaneous injection of cells grown in the presence or absence of benzyl- $\alpha$-GalNAc, and subcutaneous tumor volume doubling times were also similar (data not shown). In a separate experiment cell line HM7 was allowed to recover from benzyl- $\alpha$-GalNAc-induced mucin inhibition in culture before assessment of liver colonization. Liver colonization after a 48-h wash out of benzyl- $\alpha$-GalNAc was similar in degree to previously untreated controls (Table III), again suggesting a role for mucin in this process.

\section{Discussion}

Alterations in cell surface and secreted glycoproteins are associated with carcinogenesis, and may play a significant role in 


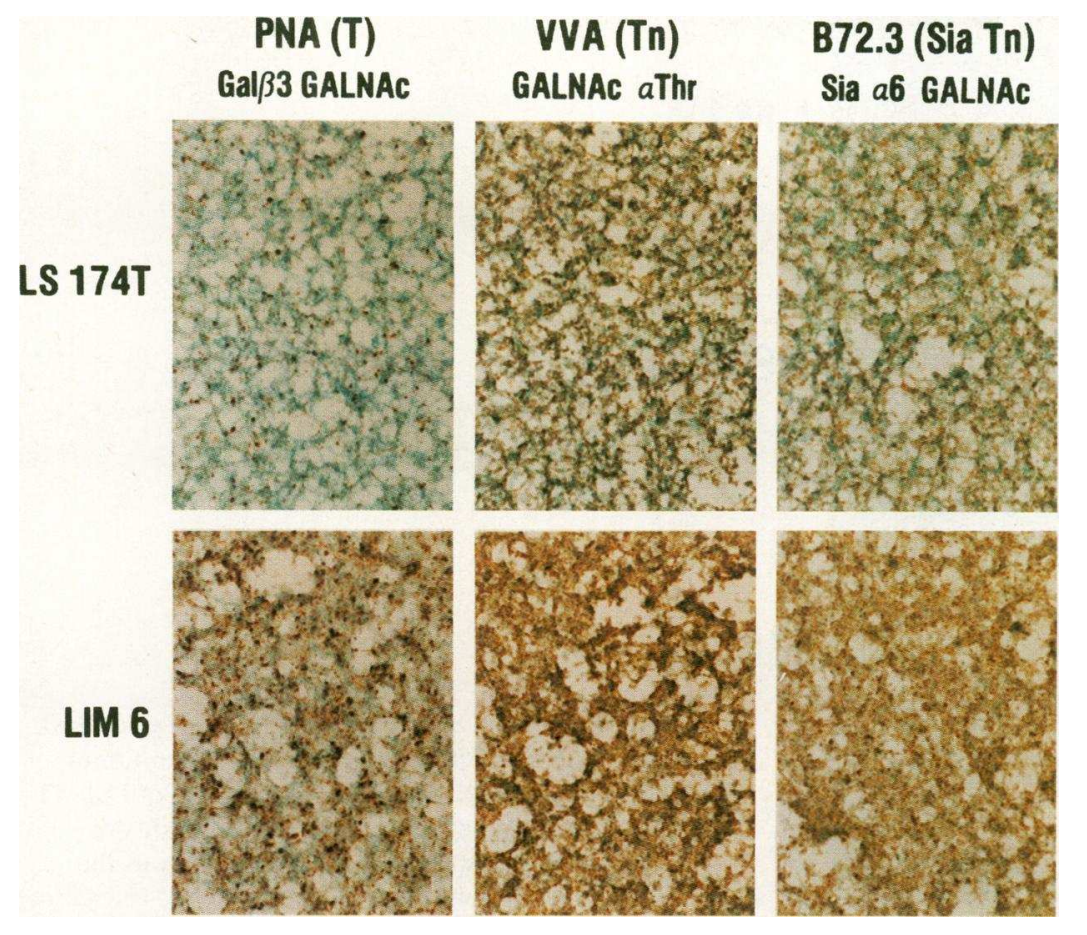

Figure 3. Immunohistochemical staining of cultured parental colon cancer cell line LS174T and its metastatic variant LS LiM 6. Cells were grown in chamber slides and examined for their expression of mucin core carbohydrate structures $\mathrm{T}, \mathrm{Tn}$, and sialyl Tn using the lectins peanut agglutinin $(P N A)$, vicia villosa agglutinin $(V V A)$, and the monoclonal antibody B72.3, respectively. Brown staining indicates a positive reaction using the streptavidinperoxidase technique. determining the metastatic behavior of tumor cells $(24,25)$. Mucins are the major secreted glycoproteins of the colon, and quantitative or qualitative changes in these high-molecular weight $O$-linked glycoproteins could alter the biological behavior of tumors arising from this epithelium (9). Mucins extracted from colon cancers may be distinct from those of the normal colon (26-30), and alterations in colonic mucin have been reported in preneoplastic conditions cush as familial polyposis (31) and ulcerative colitis (32). Histochemical and immunohistochemical studies have demonstrated differences in lectin reactivity and carbohydrate antigen expression between mucins of normal colon, colon cancer, and preneoplastic colonic adenomas $(23,26,33-35)$. Colon cancer cells of high metastatic potential may produce mucins which lack certain exposed oligosaccharide receptors $(30,36)$, and may differ in

Table I. Metastatic Abilities of Human Colon Cancer Cells

\begin{tabular}{lcccc}
\hline & \multicolumn{3}{c}{ Number of metastasis-bearing mice* } \\
\cline { 2 - 4 } $\begin{array}{l}\text { Cell } \\
\text { line }\end{array}$ & \multicolumn{3}{c}{ Liver } & $\begin{array}{c}\text { Regional } \\
\text { lymph nodes }\end{array}$ \\
\cline { 2 - 5 } LM 12 & Parenchyma & Hilus & Total & $0 / 12$ \\
LS174T & $0 / 12$ & $0 / 12$ & $0 / 12$ & $2 / 12$ \\
HM 7 & $1 / 12$ & $0 / 12$ & $1 / 12$ & $11 / 12^{11}$
\end{tabular}

Metastatic potential of cancer cells after injection and formation of experimental cecal primary tumors. Animals were sacrificed 6 wk after injection of $5 \times 10^{6}$ cells into the cecal wall. * Parenchymal metastases are those present within the substance of the liver. Hilar metastases represent cases where tumor was present within the portal vein and lymphatics of the liver hilus. ${ }^{\ddagger} P<0.02$ vs. LS174T or LM 12. ${ }^{8} P<0.002$ vs. LS174T or LM 12. " $P<0.001$ vs. LS174T or LM 12. their expression of sialylated mucin-associated structures (37, 38). Patients with mucinous adenocarcinomas of the colon often present with advanced disease and have a poor prognosis (1-6). The relationship between the amount of mucin produced by these tumors and their biological behavior, however, remains unclear (9). Because colon cancer-related mortality is most closely associated with the extent of metastasis at diagnosis, we have studied the relationship between mucin production by human colon carcinoma cells and metastasis using animal models of colon cancer metastasis which simulate human disease $(7,8,16)$.

LS LiM 6, a cell line derived from parental human colon cancer line LS174T, was selected for its ability to metastasize to the liver parenchyma during orthotopic growth in the cecum of nude mice. These cells are therefore capable of participation in all stages of the metastasis cascade $(25,39)$ which simulate human disease $(7,8)$. Their ability to participate in the terminal stages of metastasis was confirmed by the high rate of liver colonization after introduction into the portal system compared to LS174T.

LS LiM 6 produced twofold more metabolically labeled

Table II. Liver Colonization after Intrasplenic Injection of Human Colon Cancer Cells

\begin{tabular}{llc}
$\begin{array}{c}\text { Cell } \\
\text { line }\end{array}$ & $\begin{array}{c}\text { Liver } \\
\text { weight }\end{array}$ & $\begin{array}{c}\text { Number of tumor } \\
\text { nodules (range) }\end{array}$ \\
\hline LM 12 & $1.22 \pm 0.07$ & $0-2$ \\
LS174T & $1.24 \pm 0.38$ & $2-30^{\prime \prime}$ \\
HM 7 & $2.36 \pm 0.87^{\ddagger}$ & $>500^{\text {sI }}$ \\
\hline
\end{tabular}

Hepatic tumor burden $3 \mathrm{wks}$ after intrasplenic injection of $10^{6}$ tumor cells $\left(n=10\right.$ animals per group). ${ }^{*}$ Mean \pm SD. ${ }^{\ddagger} P<0.05$ vs. LM 12. ${ }^{8} P<0.001$ vs. LS174T. " $P<0.001$ vs. LM 12 . 


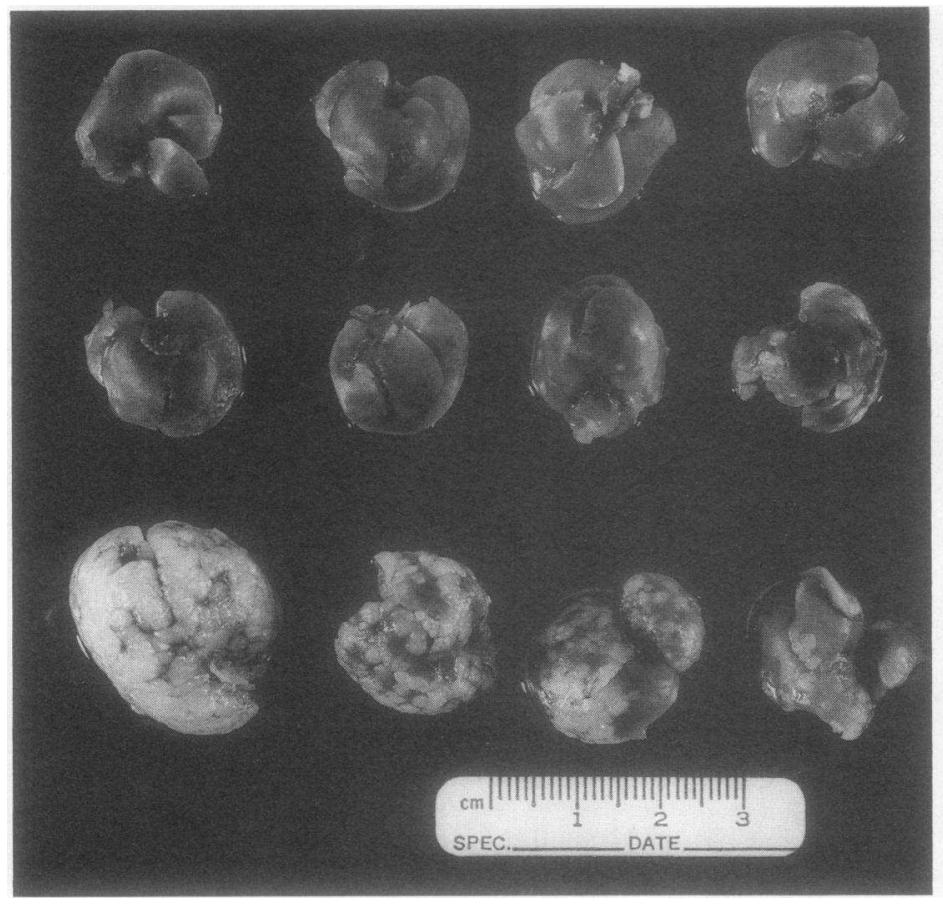

\section{LM12 \\ LS174T}

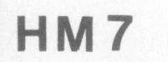

Figure 4. Livers from athymic nude mice $3 \mathrm{wk}$ after intrasplenic injection of human tumor cells. LM 12 and HM 7 are variants of LS174T which produce low and high amounts of mucin, respectively, in comparison to the parental cell line.

intracellular mucin and secreted four- to fivefold more mucin into the culture medium compared with poorly metastatic LS174T, as determined by size exclusion chromatography. The mucinous nature of this material has been previously established for LS174T and several of its derivatives $(9,10)$ and was confirmed for the metastatic variant. $\operatorname{Poly}(\mathrm{A})^{+}$messenger RNA encoding the mucin apoprotein was similarly elevated in LS LiM 6 compared to the parental line, as were three partially glycosylated mucin-associated core structures. Thus, multiple lines of evidence confirm increased mucin synthesis by the highly metastatic cell line.

In a second set of experiments, variants of LS174T selected for high (HM 7) or low (LM 12) mucin-synthesizing capacity were compared for their ability to metastasize and colonize the liver of nude mice. These cell lines have been previously shown to produce quantitatively high or low amounts of metabolically
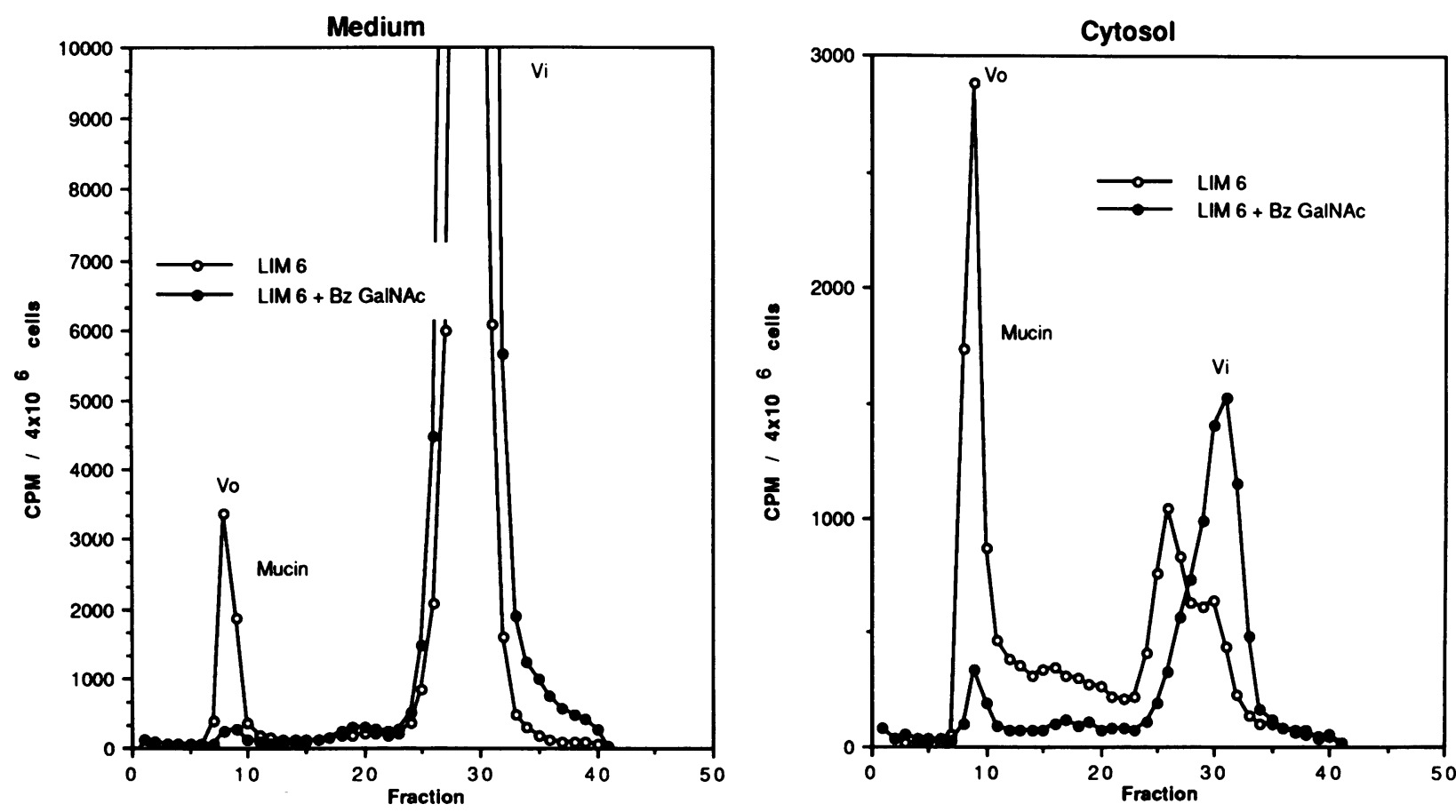

Figure 5. Sepharose CL-4B profiles of $\left[{ }^{3} \mathrm{H}\right]$ glucosamine-labeled glycoproteins secreted into the medium or from the cytosol fractions of human colon cancer cell line LS LiM 6 grown for $48 \mathrm{~h}$ in the presence or absence of $2 \mathrm{mM}$ benzyl- $\alpha-N$-acetylgalactosamine (BzGalNAc). A similar inhibition of mucin production by benzyl- $\alpha$-GalNAc has been demonstrated for cell lines LS174T and HM 7 (data not shown). 


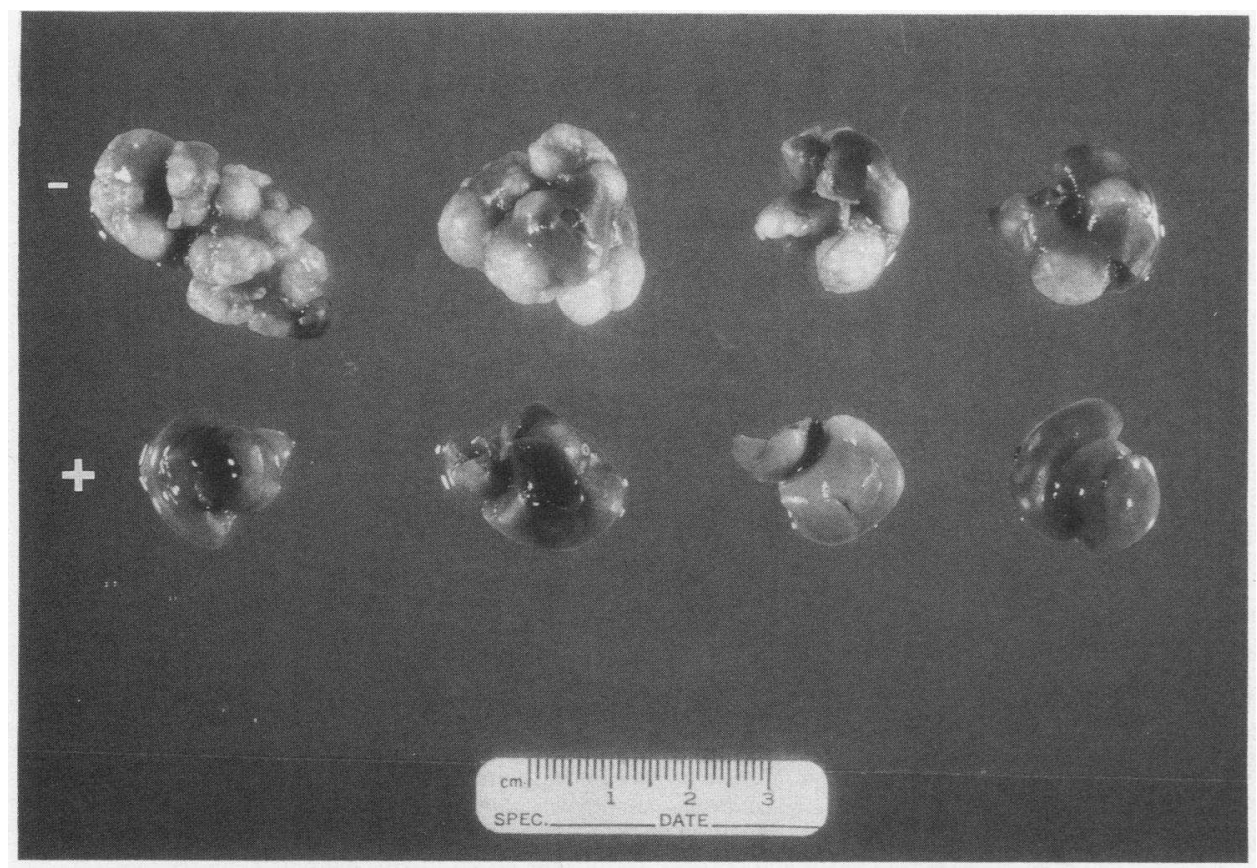

Figure 6. Livers from athymic nude mice $3 \mathrm{wk}$ after intrasplenic injection of human colon cancer cell line HM 7 grown in the presence $(+)$ or absence (-) of benzyl- $\alpha-N$ acetylgalactosamine. labeled mucin compared with the parental cell line. Few metastases to the liver or regional lymph nodes were evident during cecal growth of LM 12 or LS174T, whereas HM 7 produced metastases to the liver hilus or parenchyma in $75 \%$ of experimental animals, and regional lymph node metastases in $90 \%$. Liver colonization after splenic-portal injection of the various cell lines was also proportional to their ability to produce mucin, suggesting a possible role for mucin in the terminal stages of metastasis. While Jessup et al. (40) did not find a correlation between mucin production and tumorigenicity or metastasis of human colon cancer cells in nude mice, their assessment was based on histological evaluation of hematoxylin-eosin stained tissue sections, and not a biochemical quantitation of mucin production.

A functional relationship between mucin-type glycopro-

Table III. Effect of Inhibition of Mucin Glycosylation on Liver Colonization by Human Colon Cancer Cells

\begin{tabular}{lcc}
\hline $\begin{array}{c}\text { Cell } \\
\text { line }\end{array}$ & $\begin{array}{c}\text { Liver } \\
\text { weight }\end{array}$ & $\begin{array}{c}\text { Number of tumor } \\
\text { nodules (range) }\end{array}$ \\
\hline HM 7 & $g$ & \\
HM $7+$ benzyl $\alpha$ GalNAc ${ }^{\prime \prime}$ & $2.45 \pm 0.80$ & $70->500$ \\
LiM 6 & $1.24 \pm 0.24^{\ddagger}$ & $2-14^{\S}$ \\
LiM $6+$ benzyl $\alpha$ GalNAc & $4.78 \pm 2.15$ & $40->500$ \\
& $1.19 \pm 0.28^{\ddagger}$ & $1-11^{\S}$ \\
\hline
\end{tabular}

Hepatic tumor burden $3 \mathrm{wk}$ after intrasplanic injection of $10^{6}$ tumor cells ( $n=9$ animals per group). Cells were grown for $48 \mathrm{~h}$ in the presence or absence of $2 \mathrm{mM}$ benzyl- $\alpha$ - $N$-acetylgalactosamine.

${ }^{*}$ Mean \pm SD. ${ }^{\ddagger} P<0.01$ vs. untreated cells. ${ }^{\S} P<0.001$ vs. untreated cells. "Hepatic tumor burden after injection of treated cells allowed to recover for $48 \mathrm{~h}$ in DMEM in the absence of benzyl- $\alpha$-GalNAc was not significantly different from that after injection of untreated controls (mean liver weight, $2.86 \pm 1.35 \mathrm{~g} ; 25->500$ tumor nodules per liver). teins and the ability of colon cancer cells to metastasize was further suggested by experiments employing benzyl- $\alpha-N$-acetylgalactosamine, a competitive inhibitor of mucin glycosylation. Growth of LS LiM 6 and HM 7 in the presence of benzyl$\alpha$-GalNAc inhibited the production of fully glycosylated mucin by $80-90 \%$ in these cells. Liver colonization after splenic-portal injection was significantly reduced for both cell lines after inhibition of mucin glycosylation. This was not the result of alterations in cell viability or tumorigicity as demonstrated in vitro by exclusion of vital dyes and growth curves (10), and in vivo by subcutaneous growth of these cells. The number of tumor cells leaving the spleen and initially reaching to liver after splenic-portal injection was not affected by growth with benzyl- $\alpha$-GalNAc, as determined by tracking of ${ }^{125}$ IdURlabeled tumor cells. This again suggests a possible role for mucin-type glycoproteins in the terminal stages of liver colonization in this model.

Tumor cell-associated glycoproteins may play a significant role in various stages of metastasis $(16,24,25,28,30,36-38$, 41-43) including invasion, tumor cell-mediated platelet aggregation, resistance to immune destruction, and tumor cell adhesion to basement membrane components and target cells. Carcinoembryonic antigen, a heavily $N$-glycosylated member of the immunoglobulin supergene family (44), is an integral cell surface component of colon carcinoma cells which is shed into the serum and may, for example, participate in the adhesion of tumor cells in the liver (40). Alterations of the glycosylation of cell surface glycoproteins may interfere with tumor cell adhesion in target organs because certain molecules may act as endogenous lectins (43). Tunicamycin, a compound which inhibits the synthesis of $\mathrm{N}$-linked glycoproteins, decreases tumor cell-endothelial binding and the ability of melanoma cells to colonize the lungs of experimental animals (45). Tunicamycin also affects the expression of the ASGP-1 sialomucin on mammary tumor ascites cells, and increases susceptibility to natural killer cell-mediated tumor cell lysis (46). Swainsonine, another inhibitor of the glycosylation of $N$-linked glycoproteins may 
also affect the late stages of liver colonization by melanoma cells (47). It is possible that benzyl- $\alpha$-GalNAc similarly inhibits the formation of $O$-linked mucin type glycoproteins necessary for heterotypic cell-cell or cell-substratum interactions in the liver. In this regard, Irimura et al. $(38,48)$ have characterized high-molecular weight mucin-type sialoglycoproteins which are differentially expressed on metastatic human colon carcinoma cells grown in culture and in tumor tissues. Mucin produced by LS174T and its derivatives is highly sialylated (12), and we have previously shown that sialic acid may play a role in the ability of murine colon cancer cells to colonize the liver (16). Immunohistochemical analysis of metastatic derivatives of LS174T in vitro (this study), and comparison of primary cecal tumors and liver metastases derived from LS174T in nude mice (37) also demonstrate quantitative differences in the expression of sialylated mucin-associated carbohydrate structures similar to those found in human tissues. Sialoglycoproteins may play a role in many stages of metastasis including adhesive interactions and resistance to immune surveilance $(16,25,38,46,48)$. This study provides further evidence that mucins are associated with colorectal cancer metastasis and liver colonization. The functional relationship of specific mucin-associated structures to the various stages of metastasis is currently under investigation.

\section{Acknowledgments}

The authors wish to thank Rita Burns for preparation of the manuscript.

Supported by the Research Service of the Veterans Administration through VA Research Associate (RSB), Merit Review (RSB, YSK), and Medical Investigator (YSK) awards, and National Cancer Institute Grant CA45967 (YSK).

\section{References}

1. Symonds, D. A., and A. L. Vickery, Jr. 1976. Mucinous carcinoma of the colon and rectum. Cancer (Phila.). 37:1891-1900.

2. DeMascarel, A., J. M. Coindre, I. deMascarel, M. Trojani, D. Maree, and B. Hoerni. 1981. The prognostic significance of specific histologic features of carcinoma of the colon and rectum. Surg. Gynecol. Obstet. 153:511-514.

3. Pihl, E., R. C. Nairn, E. S. R. Hughs, A. M. Cuthbertson, and A. J. Rollo. 1980. Mucinous colorectal carcinoma: immunopathology and prognosis pathology. 12:439-447.

4. Umpleby, H. C., D. L. Ranson, and R. C. N. Williamson. 1985. Peculiarities of mucinous colorectal carcinoma. Br. J. Surg. 71:715-718

5. Sadahiro, S., T. Ohmura, S. Toshiaki, and S. Akatsuka. 1989. An assessment of the mucous component in carcinoma of the colon and rectum. Cancer (Phila.). 64:1113-1116.

6. Minsky, B. D., C. Mies, T. A. Rich, A. Recht, and J. T. Chaffey. 1987. Colloid carcinoma of the colon and rectum. Cancer (Phila.). 60:3103-3112.

7. Bresalier, R. S., S. E. Raper, E. S. Hujanen, and Y. S. Kim. 1987. A new animal model for human colon cancer metastasis. Int. J. Cancer. 39:625-630.

8. Bresalier, R. S., and Y. S. Kim. 1990. Characterization of colon carcinoma cell metastases in model systems. In Colon Cancer Cells. M. P. Mayer and G. H. Poste, editors. Academic Press, Inc., San Diego. 341-368.

9. Kuan, S.-F., J. C. Byrd, C. B. Basbaum, and Y. S. Kim. 1987. Characterization of quantitative mucin variants from a human colon cancer cell line. Cancer Res. 47:5715-5724.

10. Kuan, S.-F., J. C. Byrd, C. Basbaum, and Y. S. Kim. 1989. Inhibition of mucin glycosylation by aryl- $N$-acetyl- $\alpha$-galactosaminides in human colon cancer cells. J. Biol. Chem. 264:19271-19277.

11. Tom, B. H., L. P. Rutzky, M. M. Jakstys, R. Oyasu, C. I. Kaye, and B. D. Kahan. 1976. Human colonic adenocarcinoma cells. I. Establishment and description of a new line. In Vitro (Rockville). 12:180-191.

12. Byrd, J. C., J. Nardelli, B. Siddiqui, and Y. S. Kim. 1988. Isolation and characterization of colon cancer mucin from xenografts of LS174T. Cancer Res. 48:6678-6685.

13. Gum, J. R., W. K. Kam, J. C. Byrd, J. W. Hicks, M. H. Sleisenger, and Y. S. Kim. 1987. Effect of sodium butyrate on human colonic adenocarcinoma cells. Induction of placental-like alkaline phosphatase. J. Biol. Chem. 262:10921097.

14. Gum, J. R., J. C. Byrd, J. W. Hicks, N. W. Toribara, D. T. A. Lamport, and Y. S. Kim. 1989. Molecular cloning of human intestinal mucin cDNAs. Sequence analysis and evidence for genetic polymorphism. J. Biol. Chem. 264:6480-6487.

15. Toribara, N. W., T. L. Sack, J. R. Gum, S. B. Ho, J. E. Shively, J. K. V. Wilson, and Y.S. Kim. 1989. Heterogeneity in the induction and expression of carcinoembryonic antigen-related antigens in human colon cancer cell lines. Cancer Res. 49:3321-3327.

16. Bresalier, R. S., R. W. Rockwell, R. Dahiya, Q.-Y. Duh, and Y. S. Kim. 1990. Cell surface sialoprotein alterations in metastatic murine colon cancer cell lines selected in an animal model for colon cancer metastasis. Cancer Res. 50:1299-1307.

17. Whitehead, J. S., F. J. Fearney, and Y. S. Kim. 1979. Glycosyltransferase and glycosidase activities in cultured human fetal and colonic adenocarcinoma cell lines. Cancer Res. 39:1259-1263.

18. LaFreniere, R., and S. A. Rosenberg. 1986. A novel approach to the generation and identification of experimental hepatic metastases in a murine model. J. Natl. Cancer Inst. 76:309-322.

19. Giavazzi, R., D. E. Campbell, J. M. Jessup, K. Cleary, and I. J. Fidler. 1986. Metastatic behavior of tumor cells isolated from primary and metastatic human colorectal carcinomas implanted into different sites in nude mice. Cancer Res. 46:1928-1933.

20. Dahiya, R., S. H. Itzkowitz, J. C. Byrd, and Y. S. Kim. 1989. ABH blood group antigen expression, synthesis, and degradation in human colonic adenocarcinoma cell lines. Cancer Res. 49:4550-4556.

21. Shi, Z.-R., S. H. Itzkowitz, and Y. S. Kim. 1988. A comparison of three immunoperoxidase techniques for antigen detection in colorectal carcinoma tissues. J. Histochem. Cytochem. 36:317-322.

22. Creeth, J., K. Bhaskar, and J. Horton. 1977. The separation and characterization of bronchial glycoproteins by density-gradient methods. Biochem. J. 167:557-569.

23. Itzkowitz, S. H., M. Yuan, C. K. Montgomery, T. Kjeldsen, H. K. Takahashi, W. L. Bigbee, and Y. S. Kim. 1989. Expression of Tn, sialosyl-Tn, and T antigens in human colon cancer. Cancer Res. 49:197-204.

24. Hakomori, S.-I. 1989. Aberrant glycosylation in tumors and tumor-associated carbohydrate antigens. Adv. Cancer Res. 52:257-331.

25. Schirmaccler, V. 1985. Cancer metastasis: experimental approaches, theoretical concepts, and impacts for treatment strategies. Adv. Cancer Res. 43:1-73.

26. Boland, C. R., C. K. Montgomery, and Y. S. Kim. 1982. Alterations in human colonic mucin occurring with cellular differentiation and malignant transformation. Proc. Natl. Acad. Sci. USA. 79:2051-2055.

27. Gold, D. V., and F. Miller. 1978. Comparison of human colonic mucoprotein antigen from normal and neoplastic mucosa. Cancer Res. 38:3204-3211.

28. Yamori, T., H. Kimura, K. Steward, D. M. Ota, K. R. Cleary, and T. Irimura. 1987. Differential production of high molecular weight sulfated glycoproteins in normal colonic mucosa, primary colon carcinoma, and metastases. Cancer Res. 47:2741-2747.

29. Boland, C. R., and G. D. Deshmukh. 1990. The carbohydrate composition of mucin in colonic cancer. Gastroenterology. 98:1170-1177.

30. Bresalier, R. S., C. R. Boland, and Y. S. Kim. 1984. Characteristics of colorectal carcinoma cells with high metastatic potential. Gastroenterology. 87:115-122.

31. Filipe, M. I., S. Mughal, and H. J. Bussey. 1980. Patterns of mucous secretion in the colonic epithelium in familial polyposis. Invest. Cell. Pathol. 3:329-343.

32. Podolsky, D. K., and K. F. Isselbacher. 1984. Glycoprotein composition of colonic mucosa: specific alterations in ulcerative colitis. Gastroenterology. 87:995-998.

33. Boland, C. R., C. K. Montgomery, and Y. S. Kim. 1982. A cancer-associated mucin alteration in benign colonic polyps. Gastroenterology. 82:664-672.

34. Bresalier, R. S., C. R. Boland, and Y. S. Kim. 1984. Regional differences in normal and cancer-associated glycoconjugates of the human colon. J. Natl. Cancer Inst. 75:249-260.

35. Yuan, M., S. H. Itzkowitz, C. R. Boland, Y. D. Kim, J. T. Tomita, A. Palekar, J. L. Bennington, B. F. Trump, and Y. S. Kim. 1986. Comparison of T antigen expression in normal, premalignant, and malignant colonic tissue using lectin and antibody immunohistochemistry. Cancer Res. 46:4841-4847.

36. Kellokumpu, I. H. 1986. Differences in lectin reactivities of cellular glycoconjugates between primary human colorectal carcinomas and their metastases. Cancer Res. 46:4620-4625.

37. Bresalier, R. S., S. B. Ho, and Y. S. Kim. 1990. Alterations in mucin type glycoproteins in human colorectal cancer metastasis. Gastroenterology. 98:A274. (Abstr.) 
38. Irimura, T., D. A. Carlson, J. Price, T. Yamori, R. Giauazzi, D. M. Ota, and K. R. Cleary. 1988. Differential expression of a sialoglycoprotein with an approximate molecular weight of 900,000 on metastatic human colon carcinoma cells growing in culture and in tumor tissues. Cancer Res. 48:2353-2360.

39. Fidler, I. J., D. M. Gersten, and I. R. Hart. 1978. The biology of cancer invasion and metastasis. Adv. Cancer Res. 28:149-250.

40. Jessup, J. M., R. Giauazzi, D. Campbell, K. R. Cleary, K. Morikawa, R. Hostetler, E. N. Atkinson, and I. J. Fidler. 1989. Metastatic potential of human colorectal carcinomas implanted into nude mice: prediction of clinical outcome in patients operated upon for cure. Cancer Res. 49:6906-6910.

41. Nicolson, G. L. 1982. Cancer metastasis. Organ colonization and cell-surface properties of malignant cells. Biochim. Biophys. Acta. 695:113-176.

42. Roos, E. 1984. Cellular adhesion, invasion and metastasis. Biochim. Biophys. Acta. 738:263-284.

43. Raz, A., and R. Lotan. 1987. Endogenous galactoside-binding lectins: a new class of functional tumor cell surface molecules related to metastasis. Cancer Metastasis Rev. 6:433-452.
44. Paxton, R. J., G. Mooser, H. Pande, T. D. Lee, and J. E. Shively. 1987. Sequence analysis of carcinoembryonic antigen: identification of glycosylation sites and homology with the immunoglobulin supergene family. Proc. Natl. Acad. Sci. USA. 84:920-924.

45. Irimura, T., R. Gonzalez, and G. Nicolson. 1981. Effects of tunicamycin on BI6 melanoma cell surface glycoproteins and bloodborne arrest and survival. Cancer Res. 41:3411-3418.

46. Bharathan, S., J. Moriarty, C. E. Moody, and A. P. Sherblom. 1990. Effect of tunicamycin on sialomucin and natural killer cell susceptibility of rat mammary tumor ascites cells. Cancer Res. 50:5250-5256.

47. Newton, S. A., S. L. White, M. J. Humphries, and K. Olden. 1989. Swainsonine inhibition of spontaneous metastasis. J. Natl. Cancer Inst. 81:1024-1028.

48. Hoff, S. D., Y. Matsushita, D. M. Ota, K. R. Cleary, T. Yamori, S.-I. Hakomori, and T. Irimura. 1989. Increased expression of sialyl-dimeric $\mathrm{Le}^{\mathrm{x}}$ antigen in liver metastases of human colorectal carcinomas. Cancer Res. 49:68836888 . 